Portland State University

PDXScholar

Civil and Environmental Engineering Faculty

Publications and Presentations

Civil and Environmental Engineering

$7-2018$

\title{
A 3D Model for Earthquake-Induced Liquefaction Triggering and Post-Liquefaction Response
}

\author{
Arash Khosravifar \\ Portland State University, karash@pdx.edu \\ Ahmed Elgamal \\ University of California - San Diego \\ Jinchi Lu \\ University of California - San Diego \\ John Li \\ University of California - San Diego
}

Follow this and additional works at: https://pdxscholar.library.pdx.edu/cengin_fac

Part of the Civil Engineering Commons, Environmental Engineering Commons, and the Structural Engineering Commons

Let us know how access to this document benefits you.

\section{Citation Details}

Khosravifar, Arash; Elgamal, Ahmed; Lu, Jinchi; and Li, John, "A 3D Model for Earthquake-Induced Liquefaction Triggering and Post-Liquefaction Response" (2018). Civil and Environmental Engineering Faculty Publications and Presentations. 451.

https://pdxscholar.library.pdx.edu/cengin_fac/451

This Post-Print is brought to you for free and open access. It has been accepted for inclusion in Civil and Environmental Engineering Faculty Publications and Presentations by an authorized administrator of PDXScholar. Please contact us if we can make this document more accessible: pdxscholar@pdx.edu. 


\title{
A 3D MODEL FOR EARTHQUAKE-INDUCED LIQUEFACTION TRIGGERING AND POST- LIQUEFACTION RESPONSE
}

\author{
Arash Khosravifar a,", Ahmed Elgamal ${ }^{\mathrm{b}}$, Jinchi Lu ${ }^{\mathrm{b}}$, and John $\mathrm{Li}^{\mathrm{b}}$ \\ ${ }^{a}$ Department of Civil and Environmental Engineering, Portland State University, Portland, OR \\ 97201, USA \\ ${ }^{\mathrm{b}}$ Department of Structural Engineering, University of California, San Diego, La Jolla, CA 92093, \\ USA
}

\section{ABSTRACT}

A constitutive soil model that was originally developed to model liquefaction and cyclic mobility has been updated to comply with the established guidelines on the dependence of liquefaction triggering to the number of loading cycles, effective overburden stress $(\mathrm{K} \sigma)$, and static shear stress $(K \alpha)$. The model has been improved with new flow rules to better capture contraction and dilation in sands and has been implemented as PDMY03 in different computational platforms such as OpenSees finite-element, and FLAC and FLAC ${ }^{3 D}$ finite-difference frameworks. This paper presents the new modified framework of analysis and describes a guideline to calibrate the input parameters of the updated model to capture liquefaction triggering and post-liquefaction cyclic mobility and the accumulation of plastic shear strain. Different sets of model input parameters are provided for sands with different relative densities. Model responses are examined under different loading conditions for a single element.

Keywords: Liquefaction; Constitutive modeling; Plasticity; Triggering; Cyclic mobility

\section{INTRODUCTION}

Soil liquefaction has been shown to be a major cause of damage to structures in past earthquakes. Several constitutive models have been developed to capture various aspects of flow liquefaction and cyclic mobility such as Manzari and Dafalias (1997), Cubrinovski and Ishihara (1998), Li and Dafalias (2000), Byrne and McIntyre (1994), and Papadimitriou et al. (2001) to name a few. Simulating soil liquefaction using numerical models offers several challenges including: (a) reasonably capturing triggering of liquefaction or the rate of pore-waterpressure (PWP) generation for sands with different relative densities under various levels of shear

\footnotetext{
* Corresponding author.

E-mail address: karash@pdx.edu (A. Khosravifar)
} 
stress, effective overburden stress and static shear stress, and (b) post-liquefaction cycle-bycycle accumulation of shear and volumetric strains.

A constitutive model was developed within classical multi-surface plasticity formulation by using a mixed stress- and strain- space yield domain to reasonably capture soil liquefaction and specifically replicate the large shear strains that occur at minimal change in stress state in laboratory results (Parra 1996; Yang and Elgamal 2000). This model was implemented into a solid-fluid fully-coupled OpenSees finite element (FE) framework (Chan 1988; Parra 1996 and Mazzoni et al. 2009). The first version of the multi-yield surface pressure dependent model (PDMY) was developed primarily to capture post-liquefaction cyclic softening mechanism and the accumulation of plastic shear deformations. The previous calibration was performed against a dataset of laboratory and centrifuge tests and the model parameters were provided for sands with different relative densities in Yang et al. (2003) and Elgamal et al. (2003). The original experimental dataset was rather limited in terms of pore-water-pressure build up; therefore, liquefaction triggering was not the primary focus in the development of the original constitutive model and the calibration was performed including engineering judgment. Since new data and established procedures that have been under development in the past 30 to 40 years have become available, it became possible to make updates to the constitutive model to capture factors that affect triggering of liquefaction, as will be explained in the following paragraphs.

Various studies employing different analytical or experimental methods have been performed in recent years that provide insights on factors that affect triggering of liquefaction. Laboratory tests have shown the effect of number of loading cycles on the cyclic shear strength of sands (e.g. Yoshimi et al, 1984). Laboratory tests, case histories and theoretical studies using critical-state soil mechanics suggest that the cyclic shear strength of sands against the triggering of liquefaction is affected by the effective overburden stress characterized by the K $\sigma$ factor (e.g. Boulanger 2003a). Furthermore, laboratory tests have shown that the cyclic resistance of sands against the triggering of liquefaction is affected by initial static shear stress which is often characterized by the $\mathrm{K} \alpha$ factor (Harder and Boulanger 1997; Boulanger 2003b). To be able to capture these effects in the model response, the contraction and dilation equations in the constitutive model were updated with a new set of equations. Specific attention was given to capture the dependency of liquefaction triggering on the number of loading cycles, effective overburden stress, and initial static shear stress. We took a model that had certain strengths in capturing post-liquefaction cyclic softening and strain accumulation, and updated it into a practical tool that can reliably capture the rate of pore-water-pressure generation, triggering of liquefaction at different number of loading cycles, overburden stress $(\mathrm{K} \sigma)$ and static shear stress $(\mathrm{K} \alpha)$ in both 2D and 3D applications.

This paper presents the basic formulation of the new model and provides calibrated parameters for sands with different relative densities. The focus of this paper is to show how the new model can capture the effects of various factors discussed above on liquefaction triggering. Despite the many input parameters required by the model, the calibration is developed with a goal to derive model input parameters using minimal data available to user (i.e. the relative density) and filling the gaps using design correlations. The calibration process has been primarily based on the correlations proposed by Idriss and Boulanger (2008) for liquefaction triggering curves. A similar calibration process can be followed when lab data are available or if other triggering 
correlations are chosen. The model responses are illustrated for single-element simulations under undrained-cyclic loading conditions.

The updated model has been implemented in OpenSees finite-element, and FLAC and FLAC ${ }^{3 D}$ finite-difference frameworks as PDMY03. The results shown in this paper are created using OpenSees framework; however, similar results can be obtained using FLAC or FLAC ${ }^{3 D}$. The source code for this model is available in public domain as part of the OpenSees computational framework (http://opensees.berkeley.edu). A user manual, a library of example files, element drivers and post-processors are available and maintained at http://soilquake.net/.

In FLAC, the solid domain is discretized by a finite difference mesh consisting of quadrilateral elements or zones (Itasca 2011). Each element is subdivided internally by its diagonals into two overlaid sets of constant-strain triangular sub-elements or subzones (resulting in four sub-elements in total for each quadrilateral element). FLAC employs a "mixed discretization technique" (Marti and Cundall 1982) to overcome the mesh-locking problem: The isotropic stress and strain components are taken to be constant over the whole quadrilateral element, while the deviatoric components are maintained separately for each triangular subelement (Itasca 2011). Similarly, the above-mentioned mixed discretization approach is also applied in FLAC ${ }^{3 D}$ (Itasca 2013) where each 8-node hexahedral element or zone is subdivided into 10 tetrahedral sub-elements.

In the soil model implementation, each sub-element (analogous to a Gauss integration

\section{CONSTITUTIVE MODEL FORMULATION} point in Finite Element method) is treated independently. A complete set of soil modeling parameters including stress state and yield surface data is maintained separately for each subelement. At each time step, the soil model is called to obtain a new stress state for each subelement given the strain increments of the sub-elements.

For FLAC and FLAC3D, site response simulations (shear beam-type response) have shown that the stress state of subzones of any given element were virtually identical and similar to the overall averaged FLAC/FLAC3D response for the element. However, further work might be required to enforce additional constraints on the sub-zone responses for general scenarios of 2D/3D soil and soil-structure interaction responses as highlighted in the works of Andrianopoulos et al. (2010), Ziotopoulou and Boulanger (2013), and Beaty (2018). This effort is currently underway.

Originally, the soil modeling code was implemented in OpenSees (written in Visual $\mathrm{C}_{++}$). The implementation in FLAC and FLAC ${ }^{3 \mathrm{D}}$ mainly involved the addition of interfaces between FLAC (or $\mathrm{FLAC}^{3 \mathrm{D}}$ ) and the existing OpenSees soil model code. It was verified that similar results are obtained using FLAC, FLAC ${ }^{3 D}$ and OpenSees for the implemented model. As such, the soil constitutive model has been compiled as a dynamic link library (DLL) with corresponding versions for FLAC (Versions 7 and 8) and FLAC ${ }^{3 D}$ (Versions 5 and 6).

Based on the original multi-surface plasticity framework of Prevost (1985), the model incorporates a non-associative flow rule and a strain-space mechanism (Yang et al. 2003; Elgamal et al. 2003) in order to reasonably simulate cyclic mobility response features. This section will briefly define the components of the material plasticity including yield function, 
115 hardening rule and flow rule. Further details on model formulations are provided in Yang and 116 Elgamal (2000) and Yang et al. (2003).

\subsection{YIELD SURFACE}

The yield function in this model is defined as conical shape multi-surfaces with a common apex located at the origin of the principal space (Figure 1). The outermost surface defines the yield criterion and the inner surfaces define the hardening zone (Iwan 1967; Mroz 1967; Prevost 1985). It is assumed that the material elasticity is linear and isotropic, and that nonlinearity and anisotropy results from plasticity (Hill 1950).

The model is implemented in the octahedral space and it is important to differentiate the horizontal plane shear stress (and strain) in 2D modeling from octahedral shear stress (and strain) in 2D and 3D modeling. The deviatoric stress is defined in Figure 1 as $\widetilde{\mathbf{s}}=\widetilde{\boldsymbol{\sigma}}^{\prime}-\mathrm{p}^{\prime} \tilde{\mathbf{I}}$ and the second invariant of deviatoric stress tensor is defined as $\mathrm{J}_{2}=\frac{1}{2}[\tilde{\mathbf{s}}: \tilde{\mathbf{s}}]$. The octahedral shear stress $\left(\tau_{\text {oct }}\right)$ is defined as:

$$
\begin{aligned}
& \tau_{\text {oct }}=\frac{1}{\sqrt{3}} \sqrt{\widetilde{\mathbf{s}}: \tilde{\mathbf{s}}} \\
& =\frac{1}{3} \sqrt{\left(\sigma^{\prime}{ }_{11}-\sigma^{\prime}{ }_{22}\right)^{2}+\left(\sigma^{\prime}{ }_{22}-\sigma^{\prime}{ }_{33}\right)^{2}+\left(\sigma^{\prime}{ }_{11}-\sigma^{\prime}{ }_{33}\right)^{2}+6 \sigma_{12}{ }^{2}+6 \sigma_{13}{ }^{2}+6 \sigma_{23}{ }^{2}}
\end{aligned}
$$

The yield surfaces are defined by setting the second invariant of the deviatoric stress surfaces and is related to the soil friction angle for the outermost yield surface. Consequently, the conical yield surface equations are defined as:

$$
3 \mathrm{~J}_{2}=\mathrm{M}^{2}\left(\mathrm{p}^{\prime}+\mathrm{p}_{\mathrm{res}}^{\prime}\right)^{2}
$$

where, $\mathrm{p}_{\mathrm{res}}^{\prime}$ is a small positive constant that defines shear strength at zero effective confining Equations 1 and 2 we get the following general relationship:

$$
\mathrm{M}=\frac{3 \tau_{\mathrm{oct}}}{\sqrt{2} \mathrm{p}^{\prime}}
$$

The parameter $M$ (in the yield surface equation) can be selected to match the shear strength exhibited in a particular stress path. The 3D implementation of the equations requires 138 that the user modifies the input friction angle in order to define any desired level of shear strength within the range defined by Triaxial compression/extension and/or simple shear.

\subsection{MODULUS REDUCTION CURVES (G/G $\left.\mathbf{G}_{\max }\right)$}

The strain vector is divided into deviatoric and volumetric components. The deviatoric strain is defined in octahedral space as: 


$$
\gamma_{\text {oct }}=\frac{2}{3} \sqrt{\left(\varepsilon_{11}-\varepsilon_{22}\right)^{2}+\left(\varepsilon_{22}-\varepsilon_{33}\right)^{2}+\left(\varepsilon_{11}-\varepsilon_{33}\right)^{2}+6 \varepsilon_{12}{ }^{2}+6 \varepsilon_{13}{ }^{2}+6 \varepsilon_{23}{ }^{2}}
$$

Note that $\varepsilon_{12}=\frac{1}{2} \gamma_{12}$, where $\gamma_{12}$ is the horizontal shear strain commonly used in engineering practice. The relationship between $\tau_{\text {oct }}$ and $\gamma_{\text {oct }}$ is defined using the shear modulus. The shear modulus at small-strains $\left(\mathrm{G}_{\max }\right)$ is stress-dependent as defined in the equation below:

$$
G_{\max }=G_{\max , r}\left(\frac{p^{\prime}}{p_{r}^{\prime}}\right)^{d}
$$

where, $G_{\text {max }, r}$ is the small-strain shear modulus at the reference effective confining stress ( $p_{r}^{\prime}$ ) specified by the user, $d$ is the stress-dependency input parameter which is typically selected as 0.5 for sands (Kramer 1996), and $p^{\prime}$ is the effective confining stress that usually changes during undrained loading.

The shear modulus reduction curves $\left(G / G_{\max }\right.$ curve) are defined either by the codegenerated hyperbolic (backbone) curve, or by a user-defined modulus-reduction curve. The codegenerated hyperbolic curve is adequate for modeling liquefaction where the soil responses in undrained-cyclic conditions. For modeling the drained-cyclic behavior (such as total-stress siteresponse analysis) the user-defined modulus-reduction curves may be more suitable to obtain the desired hysteretic loops. The shape of the code-generated hyperbolic curve is stress dependent as defined in the equation below:

$$
\tau_{\mathrm{oct}}=\frac{\mathrm{G}_{\mathrm{max}}}{1+\frac{\gamma_{\mathrm{oct}}}{\gamma_{\mathrm{r}}}\left(\frac{\mathrm{p}_{\mathrm{r}}^{\prime}}{\mathrm{p}^{\prime}}\right)^{\mathrm{d}}}\left(\gamma_{\mathrm{oct}}\right)
$$

where, $G_{\text {max }}$ is the small-strain shear modulus at an effective confining stress $p^{\prime}$, and $p_{r}^{\prime}$ is the reference effective confining stress defined previously. Parameter $d$ is a model input parameter that defines the change in the shape of the backbone curve with respect to the effective confining stress (this is the same parameter defined above that defines the dependency of $G_{\max }$ to the effective confining stress). $\gamma_{\mathrm{r}}$ is an internally-calculated shear strain to define the shape of the backbone curve.

Alternatively, the model provides the flexibility to manually define the shear stress-strain relationship by specifying the modulus reduction curve in a form of pairs of $G / G_{\max }$ and $\gamma_{12}$. Methods to define strength compatible modulus reduction curves are described in detail in Gingery and Elgamal (2013).

\subsection{HARDENING RULE}

Following Mroz (1967) and Prevost (1985), a purely deviatoric kinematic hardening rule was employed to generate hysteretic response. This rule maintains the Mroz (1967) concept of conjugate-points contact, with slight modifications in order to enhance computational efficiency 
172 (Parra 1996, Elgamal et al. 2003). For drained cyclic shear loading, this means that the model 173 essentially exhibits Masing loading/unloading behavior.

\subsection{FLOW RULE}

The flow rule equations (contraction and dilation) in the original model were developed primarily to capture the cyclic mobility mechanism including the accumulation of post-liquefaction plastic shear strains and the subsequent dilative phases observed in liquefied soil response. The new updates to the flow rules enable the user to better control the rate of pore-water-pressure generation and subsequently the triggering of liquefaction.

Plastic strain increments are defined using outer normal tensors to the yield surface $(\widetilde{\mathbf{Q}})$

\subsubsection{Contractive Phase}

Shear-induced contraction occurs inside the PT surface $\left(\eta<\eta_{P T}\right)$, as well as outside $(\eta>$

$\eta_{P T}$ ) when $\dot{\eta}<0$. The adopted sign convention is such that normal stresses are positive in compression. The contraction flow rule is defined as:

$$
\begin{gathered}
\mathrm{P}^{\prime \prime}=-\mathrm{C}\left(1-\operatorname{sign}(\dot{\eta}) \frac{\eta}{\eta_{P T}}\right)^{2}\left(\mathrm{c}_{\mathrm{a}}+\varepsilon_{\mathrm{c}} \mathrm{c}_{\mathrm{b}}\right)\left(\frac{\mathrm{p}^{\prime}}{\mathrm{p}_{\mathrm{atm}}}\right)^{\mathrm{c}_{\mathrm{c}}} \\
\mathrm{C}=\left[1+\left(c_{\mathrm{d}} \cdot\left|C S R-C S R_{0}\right|\right)^{3}\right] \times\left[1+c_{\mathrm{e}} \cdot C S R_{0}\right]^{2} \\
\mathrm{CSR}=\frac{\sqrt{\tau_{12^{2}}+\tau_{23^{2}+\tau_{13}{ }^{2}}}}{p_{0}{ }^{\prime}}
\end{gathered}
$$

where, $\mathrm{c}_{\mathrm{a}}$ to $\mathrm{c}_{\mathrm{e}}$ are model input parameters. $\varepsilon_{\mathrm{c}}$ is a non-negative scalar that represents the accumulative volumetric strain (it increases by dilation and decreases by contraction). The term

$200 \varepsilon_{\mathrm{c}} \mathrm{c}_{\mathrm{b}}$ is a means to account for the fabric damage in a simplified approach, i.e. a strong dilation 201 results in higher contraction in the subsequent unloading cycle. This behavior is observed in 
experiments and is accounted for in various degrees of robustness in other similar constitutive models (Dafalias and Manzari 2004; Papadimitriou et al. 2001). The C parameter encapsulates new updates to capture the effects of the number of loading cycles and the static shear stress, which will be described later in this section. The $c_{a}$ and $c_{b}$ parameters were in the original model. To preserve the continuity with the original model we kept the shape of the equation.

The effect of input parameter $c_{a}$ on the contraction rate is shown in Figure 2 for an

faster pore water pressure build-up and larger reduction in the vertical effective stress.

The effect of input parameter $c_{b}$ on the contraction rate is shown in Figure 3 for an undrained cyclic simple shear simulation. The first dilation is denoted in the figure. In the case where fabric damage is activated (i.e. $c_{b}=5.0$ ) the accumulated volumetric strain $\left(\varepsilon_{c}\right)$ in the first dilation results in a more contractive behavior in the subsequent unloading cycle.

One of the main improvements to the original model was made by incorporating the effects of effective overburden stress on the contraction rate, also known as the $k_{\sigma}$ effect. This effect is controlled through an input parameter $\mathrm{c}_{\mathrm{c}}$ and is shown in Figure 4. A sample with higher initial effective overburden stress $\left(\sigma^{\prime}{ }_{v o}=800 \mathrm{kPa}\right)$ tends to be more contractive compared to a sample with smaller initial effective overburden stress $\left(\sigma^{\prime}{ }_{v o}=100 \mathrm{kPa}\right)$ when subjected to the same shear stress ratio $\left(\tau_{12} / \sigma^{\prime}{ }_{v o}\right)$ in an undrained simple shear simulation.

Additional improvements to the constitutive model were made by introducing parameter $\mathrm{C}$ to the contraction equation as shown in Equations $7 \mathrm{~b}$ and $7 \mathrm{c}$. The variables CSR and CSR $\mathrm{R}_{0}$ are the shear stress ratios, and $\mathrm{P}_{0}$ is the initial mean effective stress. The index "0" in these variables denotes the initial value of the variables before the application of cyclic shear stress (after consolidation).

It is common to calibrate input parameters of the model to liquefy at a shear stress ratio corresponding to earthquake magnitude $M=7.5$ and effective overburden stress $\sigma_{v}^{\prime}=1$ atm $\left(\mathrm{CSR}_{\mathrm{M}=7.5, \mathrm{OV}=1 \mathrm{~atm}}\right)$. This will anchor the CSR versus number of loading cycles curve to the point corresponding to the desired CSR and 15 uniform cycles (as shown for the two curves in Figure 5). The experimental data show that the b-value of the power fit for curves in Figure 5 should be approximately 0.34 for undisturbed frozen samples of clean sands (Yoshimi et al. 1984; Idriss and Boulanger 2008). The original model was found to have a b-value close to 0.52 (the curve with the flag parameter set to "off" or $c_{d}=0$ in Figure 5). The model response was improved in the updated model by introducing the first term on Equation $7 \mathrm{~b}$ (controlled by input parameter $\mathrm{c}_{\mathrm{d}}$ ). The updated model response has a b-value close to 0.33 (the curve with the flag parameter set to "on" or $c_{d}=16$ in Figure 5). It needs to be mentioned that other experimental studies on reconstituted sand samples suggest that the b-values can be much smaller than 0.34 (e.g. Silver et al. 1976 and Toki et al. 1986). Calibration for such a lower b-value can be performed with a possible change of the exponent " 3 " in Equation $7 \mathrm{~b}$. In this regard, additional work in currently underway.

The original model was also found to be relatively insensitive to the effects of static shear stress on liquefaction triggering (resulting in a Ka close to unity). The model was updated by introducing the second term to the flow rule in Equation $7 \mathrm{~b}$ (controlled by input parameter $\mathrm{c}_{\mathrm{e}}$ ). The $\mathrm{CSR}_{0}$ term in this equation represents the static shear stress ratio. Comparisons of the $\mathrm{Ka}$ 
parameter obtained from the updated model and experimental results are provided later. Since the additional terms presented in Equation $7 \mathrm{~b}$ are a function of CSR and CSR0, the model works well for problems where liquefaction is induced by seismically-induced shear wave propagation (resulting mainly in cyclic simple shear-type loading). It also captures the effects of the initial static shear stress (i.e. Ka) for situations of sloping ground.

\subsubsection{Dilative Phase}

The dilative phase was developed in the original model to primarily capture cyclic mobility and post-liquefaction accumulation of shear strain. The equation for dilation was updated in the new model to capture the effects of effective overburden stress as shown by parameter $d_{c}$ in the equation below. Dilation occurs only due to shearing outside the PT surface $\left(\eta>\eta_{P T}\right.$ and $\left.\dot{\eta}>0\right)$. The dilation flow rule is defined as:

$$
\mathrm{P}^{\prime \prime}=\left(1-\operatorname{sign}(\dot{\eta}) \frac{\eta}{\eta_{P T}}\right)^{2}\left(\mathrm{~d}_{\mathrm{a}}+\gamma_{\mathrm{d}} \mathrm{d}_{\mathrm{b}}\right)\left(\frac{\mathrm{p}_{\mathrm{atm}}}{\mathrm{p}^{\prime}}\right)^{\mathrm{d}_{\mathrm{c}}}
$$

256

257

258

259

260

261

262

263

where, $d_{a}, d_{b}$, and $d_{c}$ are the model input parameters. Variable $\gamma_{d}$ is an octahedral shear strain accumulated from the beginning of a particular dilation cycle as long as no significant load reversal happens. As a result, dilation rate increases as the shear strain in a particular cycle increases. A significant unloading that leads to dilation in the opposite direction will reset $\gamma_{d}$ to zero.

The effects of input parameter $d_{a}$ can be better observed on the shear stress-strain space in Figure 6. Decreasing $d_{a}$ reduces the dilative tendency and that, in return, increases the accumulated shear strain per cycle. Therefore, input parameter $d_{a}$ can be used to adjust the accumulated shear strain per cycle to the desired range.

The effects of input parameter $d_{b}$ are shown in Figure 7. The term $\gamma_{d} d_{b}$ in Equation 8 accounts for the fabric damage. To assess the effects of this factor on strain accumulation it should be noted that $\gamma_{\mathrm{d}}$ is the octahedral shear strain accumulated in a single dilative cycle and it usually takes a value smaller than 1 in common engineering applications. Therefore, changing $d_{b}$ from 3.0 to 0.3 increases the term $v_{d}{ }^{d_{b}}$ and results in a stronger dilative tendency which, in return, results in a smaller shear strain accumulation per cycle. The recommended value for $d_{b}$ is 3.0 but the user can change it for a soil-specific calibration.

\subsubsection{Neutral Phase}

When the stress state approaches the PT surface $\left(\eta=\eta_{P T}\right)$ from below, a significant amount of permanent shear strain may accumulate prior to dilation, with minimal changes in the shear stress and $p^{\prime}$, implying that $p^{\prime \prime} \approx 0$. For simplicity, this phase is modeled by maintaining $p^{\prime \prime}=0$ during this highly yielding phase, until a boundary defined in the deviatoric strain space is reached, with subsequent dilation thereafter. This concept is shown in Figure 8 and is denoted by phases 4 to 5 and 7 to 8 . This domain will enlarge or translate depending on load history. The transformation of yield domain is explained in detail in Yang et al. (2003). 


\section{MODEL CALIBRATION TO ENGINEERING PARAMETERS}

282

283

284

285

286

287

288

289

290

The primary focus in the calibration process was to capture earthquake-induced liquefaction triggering and post-liquefaction cyclic mobility based on empirical or mechanicsbased correlations suggested by other researchers for siliceous clean sands. For a specific type of sand (e.g., calcareous sand) the model parameters should be calibrated to simulate the desired response based on experimental results. In light of relative complexity of the model and input parameters, the calibration is developed such that the user can extract the input parameters based solely on relative density $\left(D_{R}\right)$ or SPT $\left(N_{1}\right)_{60}$ values for clean sand. For sands with significant fines content, the SPT $\left(\mathrm{N}_{1}\right)_{60}$ values can be modified using correlations proposed by others (for example Idriss and Boulanger 2008).

The updated model was calibrated for plane-strain cyclic-undrained conditions. The analyses were performed in the OpenSees FE platform using the PDMY03 model. Table 1 provides the proposed calibrated input parameters for PDMY03 for four different relative densities. Table 2 provides a brief description for each parameter and the adopted calibration procedure.

\section{MODEL RESPONSES}

This section presents an element-level response of the model under undrained cyclic shear loading conditions. The simulations are performed for a range of different relative densities, cyclic stress ratios, effective overburden stresses, and static shear stresses. The results are used to show the model's response against design relationships that are typically used to characterize and evaluate the dependence of liquefaction triggering to various factors such as the number of loading cycles, overburden effective stress, and static shear stress.

\subsection{EXAMPLE MODEL RESPONSE IN UNDRAINED CYCLIC LOADING}

Example element-level responses of cyclic simple shear tests (DSS) in undrained conditions are presented in this section. The analyses were performed in OpenSees FE platform with 9-4-QuadUP elements. The responses are shown for the Gauss integration point in the middle of the element. As described earlier, the contraction flow rule of the model was updated to account for the effects of initial static shear stress. This was achieved by incorporating the initial shear stress ratio in the contraction flow rule equation (i.e. CSR 0 in Equation $7 \mathrm{~b}$ ). In a DSS simulation, a non-zero initial shear stress can be induced due to a locked-in horizontal shear stress $\left(\tau_{x y, 0}\right)$ to represent a sloped ground. The element was first consolidated under a vertical stress and drained conditions with boundaries fixed horizontally. The Poisson's ratio was set to 0.33 resulting in lateral earth pressure of $\mathrm{K}_{0}=0.5$ during the gravity application. Subsequently, the element was subjected to shear cyclic loading. To simulate undrained conditions, the permeability was set sufficiently low to avoid drainage during shear loading (i.e. $1 \mathrm{e}-8 \mathrm{~m} / \mathrm{s}$ ). The automatically generated modulus reduction curves $\left(G / G_{\max }\right)$ were adopted in these analyses. Figure 9 shows representative simulation results of an undrained cyclic shear loading on a sand with $\left(N_{1}\right)_{60}=5$ under the effective confining stress of $1 \mathrm{~atm}$ and no static shear stress $(\alpha=0)$. The 
element is subjected to a cyclic shear stress ratio (CSR) of 0.09 which results in a single-amplitude shear strain of $3 \%$ after 15 cycles.

\subsection{RATE OF EXCESS PORE WATER PRESSURE GENERATION IN UNDRAINED LOADING}

Figure 10 shows the normalized excess pore water pressures for different relative densities as a function of normalized number of loading cycles. Also shown in this figure is the range of experimental observations reported by Lee and Albaisa (1974). The model response is reasonably bounded by the experimental data.

\subsection{EFFECTS OF NUMBER OF LOADING CYCLES ON LIQUEFACTION TRIGGERING}

Figure 11 shows the cyclic stress ratio (CSR) to trigger liquefaction versus the number of

\subsection{EFFECTS OF STATIC SHEAR STRESS ON LIQUEFACTION TRIGGERING (K $\alpha)$} loading cycles in undrained cyclic shear simulations. The results are shown for sands with $\left(\mathrm{N}_{1}\right)_{60}$ values of 5,15 and 25 (corresponding to relative densities $\left(D_{R}\right)$ of 33,57 and $74 \%$ ) under confining effective stress of 1 and $8 \mathrm{~atm}$. The CRR is defined here as the ratio of horizontal shear stress $\left(\tau_{12}\right)$ to effective vertical stress $\left(\sigma_{v o}^{\prime}\right)$. The criterion for triggering of liquefaction is defined in this study as the moment at which a single-amplitude shear strain of $3 \%$ is reached. The model was calibrated to trigger liquefaction in 15 loading cycles at the CRR values estimated from the correlations by Idriss and Boulanger (2008) and a vertical effective stress of $\sigma_{v o}^{\prime}=1 \mathrm{~atm}$. Also shown in this figure are the simulation results for the effective vertical stress of $\sigma^{\prime}{ }_{v o}=8 \mathrm{~atm}$. The reduction in CSR due to a higher effective overburden stress is known as the K $\sigma$ effect which is discussed in the next section. Each curve in Figure 11 is fitted with a power function (CSR $=$ a. $\mathrm{N}^{-}$ b). The power (b-value) is shown for each curve ranging from 0.29 to 0.35 . Experimental data suggest that the typical values for the power (b-value) should be approximately 0.34 for undisturbed frozen sand samples (Yoshimi et al. 1984). The updated contraction equation results in a reasonable agreement between the b-values from simulations and experiments.

\subsection{EFFECTS OF EFFECTIVE OVERBURDEN STRESS ON LIQUEFACTION TRIGGERING $(\mathrm{K} \sigma)$}

The dependence of CRR to the effective overburden stress is characterized by K $\sigma$ which is defined as $K_{\sigma}=C R R_{\sigma^{\prime}{ }_{v}} / C R R_{\sigma^{\prime} v_{v}=1 \mathrm{~atm}}$. Figure 12 shows $\mathrm{K} \sigma$ from simulation results for effective overburden stresses ranging from 1 to 8 atm for sands with $\left(N_{1}\right)_{60}$ values of 5,15 and 25 . The recommended values by Idriss and Boulanger (2008) are also shown in this figure. As implied from this figure, the model response is in good agreement with the recommended values across a wide range of effective overburden stress.

The influence of the static shear stress on liquefaction resistance is typically accounted for by a correction factor called $\mathrm{K} \alpha$ defined as $K_{\alpha}=C R R_{\alpha} / C R R_{\alpha=0}$ (Seed and Idriss 1982). The 
in-situ static shear stresses are usually induced from sloped grounds. The majority of experimental studies on the K $\alpha$ effects are performed using DSS tests with locked-in horizontal shear stresses (e.g. Harder and Boulanger 1997). Some experiments are also performed using Triaxial tests with anisotropic conditions (e.g. Vaid and Chern 1985). The Ka factors in this study were evaluated in the context of locked-in static shear stress in simple shear simulations to represent the response of sloped ground. Model simulations were performed for a range of static shear stress ratios $(\alpha)$ under vertical effective stress of $\sigma^{\prime}{ }_{v 0}=1$ atm and the $K \alpha$ factors were subsequently generated for a range of relative densities. In each simulation, the vertical confinement and static shear stress were first applied statically under drained conditions. Thereafter, the element was subjected to undrained cyclic loading with CSR adjusted such that it would reach $3 \%$ single-amplitude shear strain in 15 cycles.

The $\mathrm{K} \alpha$ factors derived from simulations are shown in Figure 13. Also shown in this figure are experimental results from Harder and Boulanger (1997). It is observed that, in general, an increase in the static shear stress ratios $(\alpha)$ results in a decrease in $\mathrm{K} \alpha$ for loose sands and an increase for dense sands. In other words, as the ground slope increases, loose sands will become more contractive and dense sand will become less contractive (more dilative). The Ka factor can be adjusted using the input parameter $c_{e}$. Experimental and numerical studies have shown that $K \alpha$ could be dependent to the effective overburden stress as well (Boulanger 2003b; Ziotopoulou and Boulanger 2016). However, the current implementation of PDMY03 does not directly account for this dependency. Future updates are possible to be implemented once sufficient laboratory data is available on the dependency of $\mathrm{K} \alpha$ to the effective overburden stress.

\section{CONCLUSIONS}

The pressure-dependent multi-yield surface constitutive model was originally developed to capture cyclic mobility and post-liquefaction accumulation of shear strains. This paper presents new updates to the constitutive model to capture the effects of various parameters on triggering of liquefaction including the effects of the number of loading cycles, the effective overburden

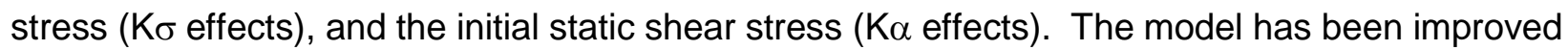
with new flow rules to better simulate contraction and dilation induced by shear strains in soils, thereby more accurate modeling of liquefaction in sandy soils. The model has been implemented in $2 \mathrm{D}$ and $3 \mathrm{D}$ numerical platforms in OpenSees finite-element, and FLAC and FLAC ${ }^{3 \mathrm{D}}$ finitedifference frameworks.

The updated model has been calibrated based on design relationships for a range of relative densities for sand. Despite many input parameters that characterize the complex response of the constitutive model, different sets of input parameters are provided for generic response based on simple data available to designers, i.e. relative density of sand. The model parameters are calibrated for typical siliceous Holocene sands with different relative densities and are provided for cases where site-specific experimental data is not available.

This paper describes the basics of the plasticity framework of the model and provides guidelines to calibrate the input parameters of the model to simulate undrained cyclic loading conditions. The model responses under high effective overburden stress $(K \sigma)$ and static shear 
400 stress $(\mathrm{K} \alpha)$ are compared to expected average behavior published by other researchers showing

401 reasonable agreements. Further developments are needed as new data become available.

\section{ACKNOWLEDGMENTS}

404

The presented modifications to more formally capture the liquefaction triggering mechanism were motivated by the vision and related pioneering PM4Sand work of Professors Boulanger and Ziotopoulou. While at UCSD, the Initiatives of Dr. Zhaohui Yang addressed this vision with a preliminary effort. Dr. James Gingery provided valuable feedback during the preparation of this manuscript. The authors would like to thank the valuable comments by the two anonymous reviewers. Partial funding was provided by the National Science Foundation (NSF award OISE-1445712).

\section{REFERENCES}

1. Andrianopoulos, K.I., Papadimitriou, A.G., and Bouckovalas, G.D. (2010). "Bounding surface plasticity model for the seismic liquefaction analysis of geostructures." Journal of Soil Dynamics and Earthquake Engineering, 30(10), 895 -911.

2. Andrus, R.D., and Stokoe, K.H. (2000). "Liquefaction resistance of soils from shear-wave velocity." Journal of Geotechnical and Geoenvironmental Engineering, ASCE, 126(11): 1015-25.

3. Beaty, M.H. (2018). "Application of UBCSAND to the LEAP centrifuge experiments." Journal of Soil Dynamics and Earthquake Engineering, 104, 143-153.

4. Boulanger, R.W. (2003a). "High overburden stress effects in liquefaction analysis," J. Geotechnical and Geoenvironmental Engineering, ASCE, 129(12), 1071-1082.

5. Boulanger, R.W. (2003b). "Relating K $\alpha$ to relative state parameter index," J. Geotechnical and Geoenvironmental Engineering, ASCE, 129(8), 770-773.

6. Byrne, P.M., and Mclntyre, J. (1994). "Deformations in granular soils due to cyclic loading," Proceedings of Settlement 94, Texas. ASCE Geotechnical Special Publication No. 401994 p. 1864-96.

7. Chan, A.H.C. (1988). "A unified finite element solution to static and dynamic problems in geomechanics." PhD dissertation, Univ. College of Swansea, Swansea, U.K.

8. Cubrinovski, M., and Ishihara, K. (1998). "Modeling of Sand Behavior Based on State Concept," Soils and Foundations, 38(3), 115-127.

9. Dafalias, Y.F., and Manzari, M.T. (2004). "Simple Plasticity Sand Model Accounting for Fabric Change Effects," J. Geotechnical and Geoenvironmental Engineering, ASCE, 130(6), 622634.

10. Elgamal, A., Yang, Z., Parra, E., and Ragheb, A. (2003). "Modeling of cyclic mobility in saturated cohesionless soils." International Journal of Plasticity, 19(6), 883-905 
11. Gingery, J.R., and Elgamal, A. (2013). "Shear stress-strain curves based on the G/Gmax logic: A procedure for strength compatibility." In IACGE 2013: Challenges and Recent Advances in Geotechnical and Seismic Research and Practices (pp. 721-729).

12. Harder, L.F., and Boulanger, R.W. (1997). "Application of Ko and Ka correction factors." Proceedings of the NCEER workshop on evaluation of liquefaction resistance of soils. Technical Report NCEER-97-0022, National Center for Earthquake Engineering Research, SUNY, pp 167-190

13. Hill, R. (1950). "The Mathematical Theory of Plasticity," Oxford Univ. Press, London.

14. Idriss, I.M., and Boulanger, R.W. (2008). "Soil liquefaction during earthquakes." Monograph MNO-12. Oakland, CA: Earthquake Engineering Research Institute; 261p.

15. Itasca (2011). "FLAC - Fast Lagrangian Analysis of Continua, Version 7.0," Itasca Consulting Group, Inc., Minneapolis, Minnesota

16. Itasca (2013). "FLAC3D - Fast Lagrangian Analysis of Continua in 3 Dimensions, Version 5.0," Itasca Consulting Group, Inc., Minneapolis, Minnesota

17. Iwan, W.D. (1967). "On a Class of Models for the Yielding Behavior of Continuous and Composite Systems," J. Applied Mechanics, ASME, 34, 612-617.

18. Kramer, S.L. (1996). Geotechnical Earthquake Engineering, Prentice Hall, NJ.

19. Lee, K.L., and Albaisa, A. (1974). "Earthquake induced settlements in saturated sands: 9F, 2T, 29R. J. Geotech. Eng. DIV. V100, N. GT4, APR. 1974, P387-406." International Journal of Rock Mechanics and Mining Sciences \& Geomechanics Abstracts. Vol. 11. No. 8. Pergamon.

20. Li, X.S., and Dafalias, Y.F. (2000). "Dilatancy for Cohesionless Soils," Geotechnique, 50(4), 449-460.

21. Manzari, M.T., and Dafalias, Y.F. (1997). "A Critical State Two-Surface Plasticity Model for Sands," Geotechnique, 49(2), 252-272.

22. Marti, J., and Cundall, P. (1982). "Mixed discretization procedure for accurate modelling of plastic collapse." International J. for Numerical and Analytical Methods in Geomechanics, 6, pp. 129-139.

23. Mazzoni, S., McKenna, F., Scott, M.H., and Fenves, G.L. (2009). "Open System for Earthquake Engineering Simulation User Manual," University of California, Berkeley.

24. Mroz, Z. (1967). "On the Description of Anisotropic Work Hardening," J. Mechanics and Physics of Solids, 15, 163-175.

25. Papadimitriou, A.G., Bouckovalas, G.D., and Dafalias, Y.F. (2001). "Plasticity Model for Sand under Small and Large Cyclic Strains," J. Geotechnical and Geoenvironmental Engineering, ASCE, 127(11), 973-983.

26. Parra, E. (1996). "Numerical Modeling of Liquefaction and Lateral Ground Deformation Including Cyclic Mobility and Dilation Response in Soil Systems," Ph.D. Thesis, Dept. of Civil Engineering, RPI, Troy, NY. 
27. Prevost, J.H. (1985). "A Simple Plasticity Theory for Frictional Cohesionless Soils," Soil Dynamics and Earthquake Engineering, 4(1), 9-17.

28. Seed, R.B., and Harder, L.F. (1990). "SPT-based analysis of cyclic pore pressure generation and undrained residual strength," Proceedings, H. Bolton Seed Memorial Symposium, J.M. Duncan (Ed.), Univ. of California, Berkeley, 2, 351-376.

29. Seed, H.B., and Idriss, I.M. (1982). "Ground motions and soil liquefaction during earthquakes" (Vol. 5). Earthquake Engineering Research Institute.

30. Silver, M.L., and Seed, H.B. (1971). "Volume changes in sand during cyclic loading," J. Soil Mechanics and Foundations Div., ASCE 97(SM9), 1171-182.

31. Toki, S., Tatsuoka, F., Miura, S., Yoshimi, Y., Yasuda, S., and Makihara, Y. (1986). "Cyclic undrained triaxial strength of sand by a cooperative test program." Soils and Foundations, 26(3), pp.117-128.

32. Vaid, Y.P., and Chern, J.C. (1985). "Cyclic and monotonic undrained response of saturated sands." Adv. Art Test Soils Under Cycl Cond, 120-47.

33. Yang, Z., Elgamal, A., and Parra, E., (2003). "Computational model for cyclic mobility and associated shear deformation," J. Geotech. Geoenviron. Eng, 129, 12, 1119-1127.

34. Yang, Z., and Elgamal, A. (2000). "Numerical Modeling of Earthquake Site Response Including Dilation and Liquefaction." Report No. SSRP-2000/01, Department of Structural Engineering, University of California, San Diego.

35. Yoshimi Y., Tokimatsu K., Kaneko O., Makihara Y. (1984). "Undrained cyclic shear strength of dense Niigata sand." Soils Found, Jpn Soc Soil Mech Found Eng 24(4):131-145.

36. Ziotopoulou, K., and Boulanger, R.W. (2013). "Calibration and implementation of a sand plasticity plane-strain model for earthquake engineering applications." Journal of Soil Dynamics and Earthquake Engineering, 53, 268-280.

37. Ziotopoulou, K., and Boulanger, R.W. (2016). "Plasticity modeling of liquefaction effects under sloping ground and irregular cyclic loading conditions." Soil Dynamics and Earthquake Engineering, 84 (2016), 269-283. 
Table 1. Model Input Parameters

\begin{tabular}{|c|c|c|c|c|}
\hline Model parameters & Loose Sand & $\begin{array}{l}\text { Medium Dense } \\
\text { Sand }\end{array}$ & Dense Sand & $\begin{array}{l}\text { Very Dense } \\
\text { Sand }\end{array}$ \\
\hline$\left(\mathrm{N}_{1}\right)_{60}{ }^{*}$ & 5 & 15 & 25 & 35 \\
\hline Relative density, $D_{R}^{*}$ & $33 \%$ & $57 \%$ & $74 \%$ & $87 \%$ \\
\hline Cyclic resistance ratio, $\mathrm{CRR}_{\sigma^{\prime} \mathrm{v}=1, \mathrm{M}=7.5^{*}}$ & 0.09 & 0.16 & 0.29 & N.A. \\
\hline Density, $\rho$ & $\begin{array}{c}1.94 \\
\text { tonne } / \mathrm{m}^{3}\end{array}$ & 1.99 tonne $/ \mathrm{m}^{3}$ & $\begin{array}{c}2.03 \\
\text { tonne } / \mathrm{m}^{3}\end{array}$ & 2.06 tonne $/ \mathrm{m}^{3}$ \\
\hline Reference mean effective pressure, $p_{r}^{\prime}$ & $101 \mathrm{kPa}$ & $101 \mathrm{kPa}$ & $101 \mathrm{kPa}$ & $101 \mathrm{kPa}$ \\
\hline $\begin{array}{c}\text { Small-strain shear modulus at reference } \\
\text { pressure, Gmax,r }\end{array}$ & $46.9 \mathrm{MPa}$ & $73.7 \mathrm{MPa}$ & $94.6 \mathrm{MPa}$ & $111.9 \mathrm{MPa}$ \\
\hline $\begin{array}{c}\text { Maximum shear strain at reference } \\
\text { pressure, } \gamma_{\text {max }, \mathrm{r}}\end{array}$ & 0.1 & 0.1 & 0.1 & 0.1 \\
\hline Bulk modulus at reference pressure, $\mathrm{Br}$ & $125.1 \mathrm{MPa}$ & $196.8 \mathrm{MPa}$ & $252.6 \mathrm{MPa}$ & $298.3 \mathrm{MPa}$ \\
\hline Pressure dependence coefficient, $d$ & 0.5 & 0.5 & 0.5 & 0.5 \\
\hline DSS friction angle, $\varphi D^{*}{ }^{*}$ & $30^{\circ}$ & $35^{\circ}$ & $40^{\circ}$ & $45^{\circ}$ \\
\hline Model friction angle, $\varphi$ & $25.4^{\circ}$ & $30.3^{\circ}$ & $35.8^{\circ}$ & $42.2^{\circ}$ \\
\hline Phase transformation angle, & $20.4^{\circ}$ & $25.3^{\circ}$ & $30.8^{\circ}$ & $37.2^{\circ}$ \\
\hline Contraction coefficient, $\mathrm{Ca}_{\mathrm{a}}$ & 0.03 & 0.012 & 0.005 & 0.001 \\
\hline Contraction coefficient, $\mathrm{Cb}$ & 5.0 & 3.0 & 1.0 & 0.0 \\
\hline Contraction coefficient, $\mathrm{c}_{\mathrm{c}}$ & 0.2 & 0.4 & 0.6 & 0.8 \\
\hline Contraction coefficient, $\mathrm{Cd}$ & 16.0 & 9.0 & 4.6 & 2.2 \\
\hline Contraction coefficient, $\mathrm{ce}_{\mathrm{e}}$ & 2.0 & 0.0 & -1.0 & 0.0 \\
\hline Dilation coefficient, $d_{a}$ & 0.15 & 0.3 & 0.45 & 0.6 \\
\hline Dilation coefficient, $\mathrm{db}$ & 3.0 & 3.0 & 3.0 & 3.0 \\
\hline Dilation coefficient, $d_{c}$ & -0.2 & -0.3 & -0.4 & -0.5 \\
\hline Number of yield surfaces, NYS & 20 & 20 & 20 & 20 \\
\hline So & $1.73 \mathrm{kPa}$ & $1.73 \mathrm{kPa}$ & $1.73 \mathrm{kPa}$ & $1.73 \mathrm{kPa}$ \\
\hline
\end{tabular}

*These are not input parameters to the constitutive model, but rather parameters computed during model calibration. 
Table 2. Description of Calibration Parameters

\begin{tabular}{|c|c|}
\hline Parameter & Description \\
\hline$\left(\mathrm{N}_{1}\right)_{60}$ & Corrected SPT blow counts normalized for overburden stress of $1 \mathrm{~atm}$. \\
\hline $\mathrm{D}_{\mathrm{R}}$ & Relative density correlated to SPT blow count using $D_{R}=\sqrt{\frac{\left(N_{1}\right)_{60}}{46}}$ from Idriss and Boulanger (2008) \\
\hline $\mathrm{CRR}_{\sigma^{\prime} v=1, \mathrm{M}=7.5}$ & $\begin{array}{l}\text { The cyclic stress ratio to trigger liquefaction under vertical effective stress of } 1 \text { atm in } 15 \text { uniform } \\
\text { loading cycles (equivalent number of uniform cycles for a magnitude } 7.5 \text { earthquake based on Seed } \\
\text { and Idriss, 1982). Triggering of liquefaction is defined here as the moment at which the material } \\
\text { reaches to a single-amplitude shear strain of } 3 \% \text {. Liquefaction triggering correlations by Idriss and } \\
\text { Boulanger (2008) were used in this calibration study: } \\
\qquad \operatorname{CRR}_{\sigma_{v}=1, \mathrm{M}=7.5}=\exp \left(\frac{\left(N_{1}\right)_{60}}{14.1}+\left(\frac{\left(N_{1}\right)_{60}}{126}\right)^{2}-\left(\frac{\left(N_{1}\right)_{60}}{23.6}\right)^{3}+\left(\frac{\left(N_{1}\right)_{60}}{25.4}\right)^{4}-2.8\right)\end{array}$ \\
\hline $\mathrm{p}_{\mathrm{r}}^{\prime}$ & $\begin{array}{l}\text { Reference mean effective pressure at which small-strain shear modulus }\left(G_{m a x, r}\right) \text { and bulk modulus } \\
\left(\mathrm{B}_{\mathrm{r}}\right) \text { are specified. It is taken as } 101 \mathrm{kPa}(1 \mathrm{~atm}) \text { in this calibration. }\end{array}$ \\
\hline $\mathrm{G}_{\max , \mathrm{r}}$ & $\begin{array}{l}\text { Small-strain shear modulus at the reference mean effective pressure }\left(p_{r}^{\prime}\right) \text { of } 1 \text { atm. } G \text { max,r was } \\
\text { calculated from the shear wave velocity estimates by Andrus and Stokoe }(2000) \text { with slight } \\
\text { modifications for very small blow counts by Ziotopoulou and Boulanger }(2013): V_{s, \sigma_{v}^{\prime}=1}= \\
85\left[\left(\mathrm{~N}_{1}\right)_{60}+2.5\right]^{0.25} \text { where } V_{s, \sigma_{v}^{\prime}=1} \text { is the shear wave velocity at vertical effective stress of } 1 \text { atm. } \\
G_{m a x, r} \text { was adjusted by a factor of } \sqrt{3 / 2} \text { to account for the change in confining pressure from } K_{o}= \\
0.5 \text { to } 1.0 \text { using } d=0.5 \text { in Equation } 5 \text {. }\end{array}$ \\
\hline$\gamma_{\max , \mathrm{r}}$ & $\begin{array}{l}\text { The octahedral shear strain at failure at the reference mean effective pressure } \mathrm{p}_{\mathrm{r}}^{\prime} \text {. This parameter } \\
\text { is set to } 0.1(10 \%) \text { in this calibration. }\end{array}$ \\
\hline $\mathrm{B}_{\mathrm{r}}$ & $\begin{array}{l}\text { The bulk modulus at reference pressure }\left(\mathrm{p}_{\mathrm{r}}^{\prime}\right) \text { is derived from the small-strain shear modulus; } \mathrm{B}_{\mathrm{r}}= \\
(\mathrm{B} / \mathrm{G}) \mathrm{G}_{\mathrm{max}, \mathrm{r}} \text {. The bulk modulus to shear modulus ratio is derived from: }(\mathrm{B} / \mathrm{G})=\frac{2(1+\vartheta)}{3(1-29)}=2.6 \text { using } \\
\text { Poisson's ratio of } \vartheta=0.33\end{array}$ \\
\hline d & $\begin{array}{l}\text { The pressure dependency coefficient defines the dependency of the small-strain shear modulus and } \\
\text { the shape of the modulus reduction curves to the effective confining stress. }\end{array}$ \\
\hline$\varphi_{\text {DSS }}$ & Friction angle obtained from direct simple shear (DSS) test. \\
\hline$\varphi$ & $\begin{array}{l}\text { The input friction angle that defines the size of the outermost yield surface. In order to achieve a } \\
\text { desired shear strength obtained from DSS tests, the input friction angle can be calculated from the } \\
\text { following equation: } \varphi=\sin ^{-1}\left[\frac{3 \tan \left(\varphi_{\text {DSS }}\right)}{2 \sqrt{3}+\tan \left(\varphi_{\text {DSS }}\right)}\right]\end{array}$ \\
\hline$\varphi_{\mathrm{PT}}$ & $\begin{array}{l}\text { The phase transformation angle is the angle over which the soil behavior changes from contractive } \\
\text { to dilative (usually a few degrees smaller than the soil friction angle). }\end{array}$ \\
\hline $\mathrm{c}_{\mathrm{a}}$ & $\begin{array}{l}\text { This parameter is the main input parameter controlling the contraction rate and subsequently the } \\
\text { pore-water-pressure generation rate (Equation } 7 \mathrm{a} \text { ). This parameter was calibrated to trigger } \\
\text { liquefaction in } 15 \text { loading cycles at a cyclic stress ratio equal to } \mathrm{CRR}_{\sigma_{v}=1, \mathrm{M}=7.5 \text {. }}\end{array}$ \\
\hline$c_{b}$ & $\begin{array}{l}\text { This parameter accounts for fabric damage. In the absence of reliable laboratory data that quantifies } \\
\text { fabric damage, this parameter was calibrated in combination with other contraction parameters to } \\
\text { capture the triggering of liquefaction. }\end{array}$ \\
\hline $\mathrm{c}_{\mathrm{c}}$ & This parameter accounts for the overburden stress effect (i.e. $K_{\sigma}$ effect). \\
\hline $\mathrm{c}_{\mathrm{d}}$ & $\begin{array}{l}\text { A new parameter introduced in the updated model to increase (decrease) the rate of contraction for } \\
\text { large (small) shear stress ratios. This feature can be disabled by setting } C_{d}=0 \text {. }\end{array}$ \\
\hline $\mathrm{c}_{\mathrm{e}}$ & $\begin{array}{l}\text { A new parameters introduced in the updated model to control the dependency of contraction rate to } \\
\text { static shear stress ratio and achieve desired } \mathrm{K} \alpha \text {. This feature can be disabled by setting } \mathrm{Ce}_{\mathrm{e}}=0 \text {. }\end{array}$ \\
\hline $\mathrm{d}_{\mathrm{a}}$ & $\begin{array}{l}\text { This parameter, combined with the difference between } \varphi \text { and } \varphi_{\mathrm{PT}} \text {, are the primary parameters to } \\
\text { control the dilation tendency after crossing the PT surface. } \mathrm{d}_{\mathrm{a}} \text { was calibrated to produce the desired } \\
\text { post-liquefaction shear strain per cycle. This parameter was calibrated simultaneously with }\end{array}$ \\
\hline
\end{tabular}




\begin{tabular}{|l|l|}
\hline & $\begin{array}{l}\text { calibrating the model to liquefy at } 15 \text { cycles with a goal to produce approximately } 1.5 \%, 1.0 \% \text {, and } \\
0.5 \% \text { post-liquefaction shear strain per cycle for }\left(\mathrm{N}_{1}\right) 60 \text { values of } 5,15 \text {, and } 25 \text { respectively. }\end{array}$ \\
\hline $\mathrm{d}_{\mathrm{b}}$ & $\begin{array}{l}\text { This parameter accounts for fabric damage in the dilation equation. In the absence of reliable } \\
\text { laboratory data that quantifies fabric damage, this parameter was calibrated in combination with } \\
\text { other dilation parameters to result in the desired post-liquefaction accumulation of shear strain. }\end{array}$ \\
\hline $\mathrm{d}_{\mathrm{c}}$ & This parameter accounts for the effects of overburden stress on the dilation rate (i.e. $\mathrm{K}_{\sigma}$ effect). \\
\hline $\mathrm{NYS}$ & \begin{tabular}{l} 
Number of yield surfaces \\
\hline $\mathrm{S}_{0}$
\end{tabular} \\
& $\begin{array}{l}\text { Shear strength at zero mean effective pressure. For sands, a post-liquefaction strength of } 2 \mathrm{kPa} \\
\text { was assumed which results in octahedral shear strength equal to } 1.73 \mathrm{kPa} \text { based on } \tau_{12, \mathrm{p}^{\prime}=0}= \\
\frac{2 \sqrt{3}}{3} \mathrm{~S}_{0}\end{array}$ \\
\hline
\end{tabular}



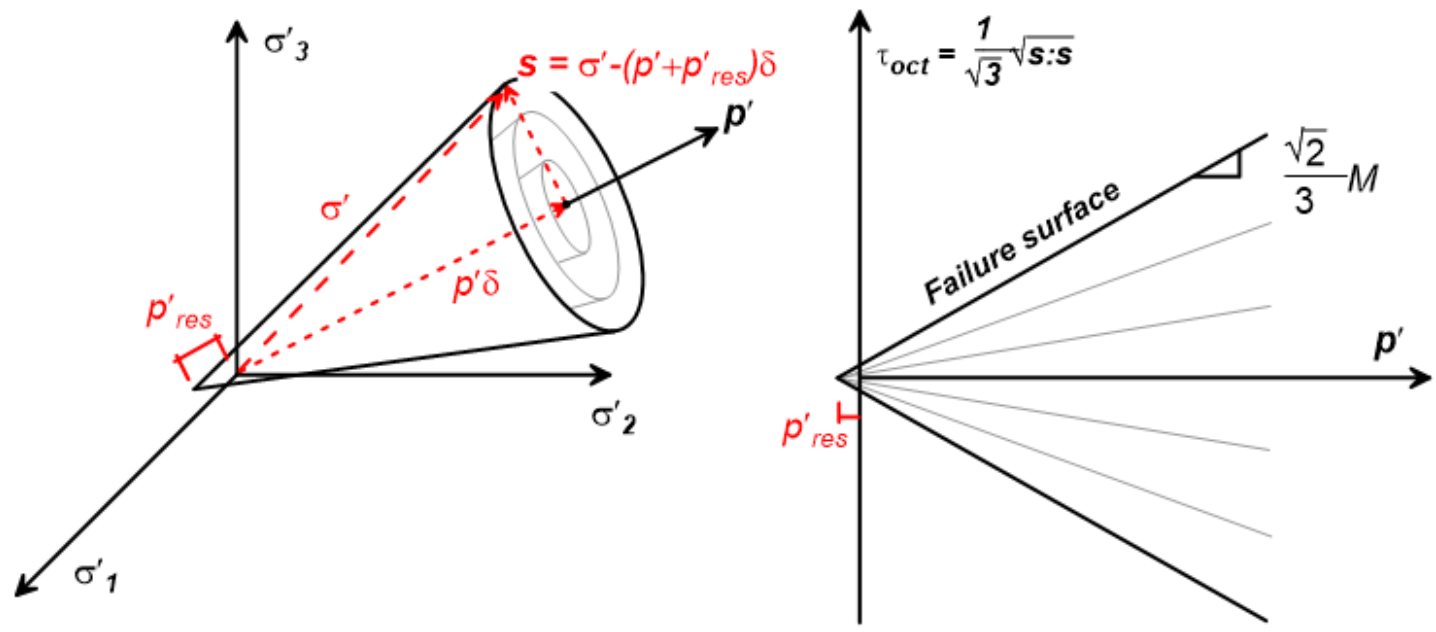

Figure 1. Conical multi-surface yield criteria in principal stress space 


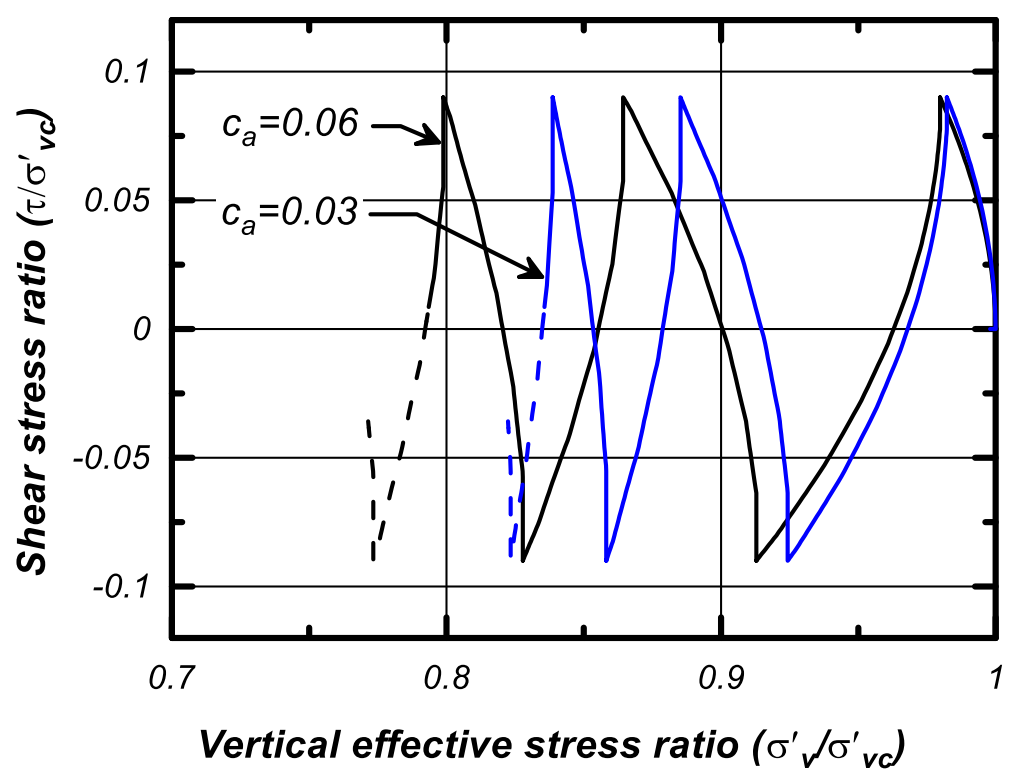

Figure 2. Effects of input parameter $\boldsymbol{c}_{\mathbf{a}}$ on contraction rate 


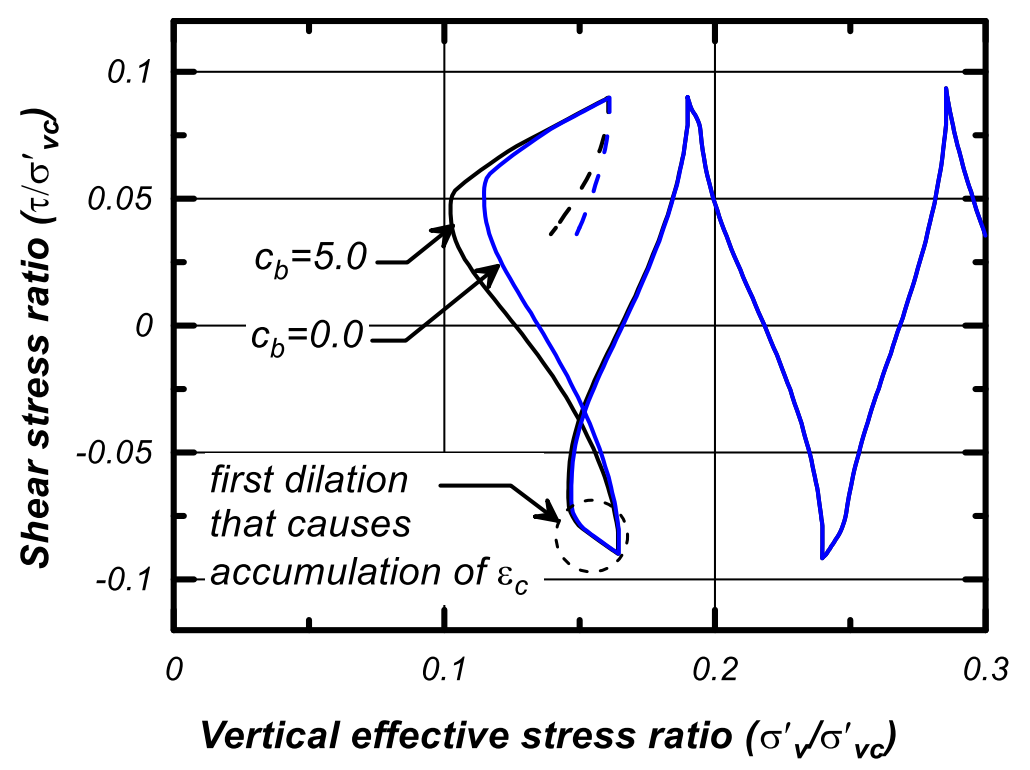

Figure 3. Effects of input parameter $\boldsymbol{c}_{\mathbf{b}}$ (fabric damage) on contraction rate 


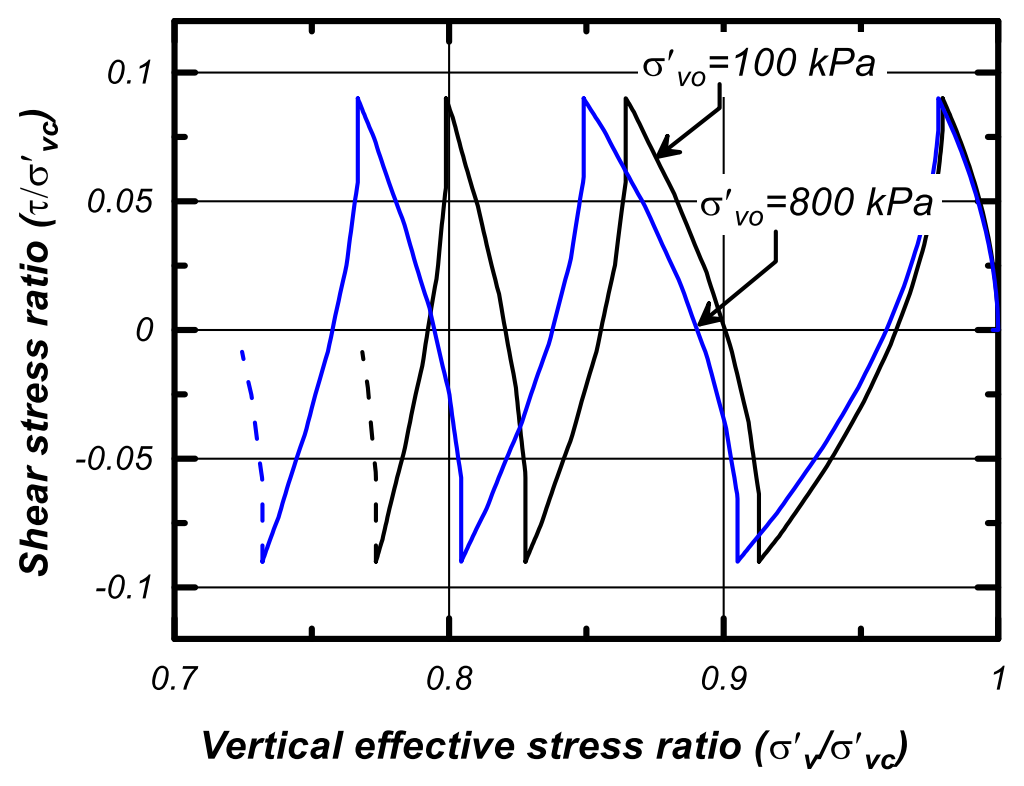

(a)

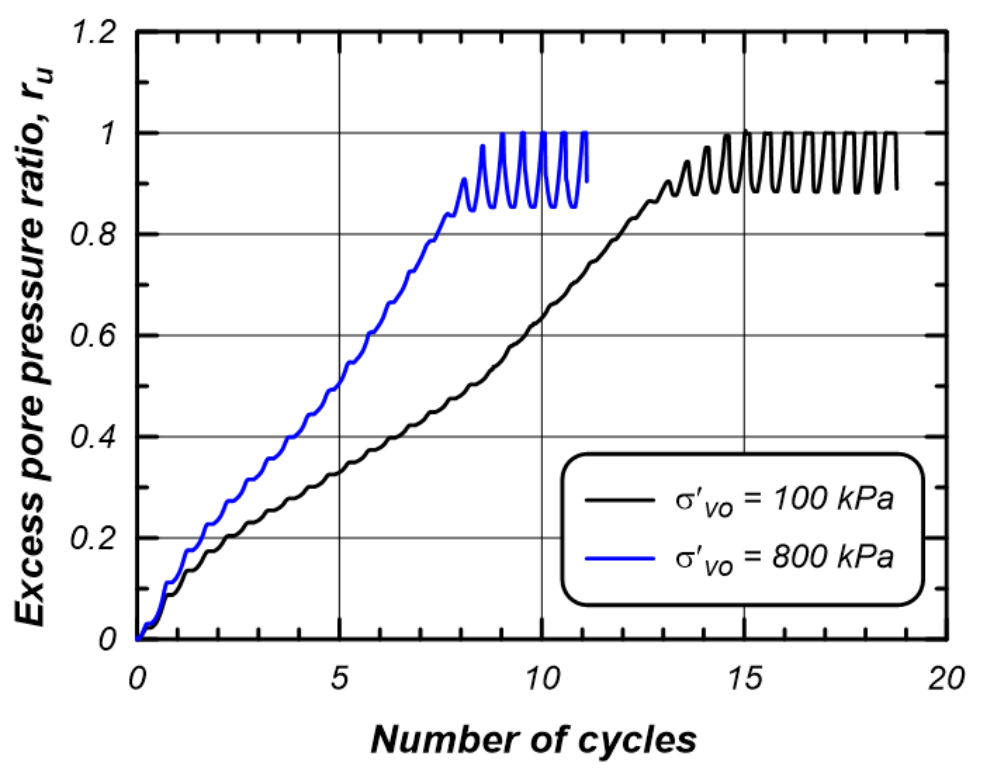

Figure 4. Effects of overburden stress on contraction rate $\left(\boldsymbol{K}_{\boldsymbol{\sigma}}\right.$ effect) for input parameter $\boldsymbol{c}_{\mathbf{c}}=$ $\mathbf{0 . 2}$; (a) stress path and (b) pore water pressure ratio versus number of shear cycles 


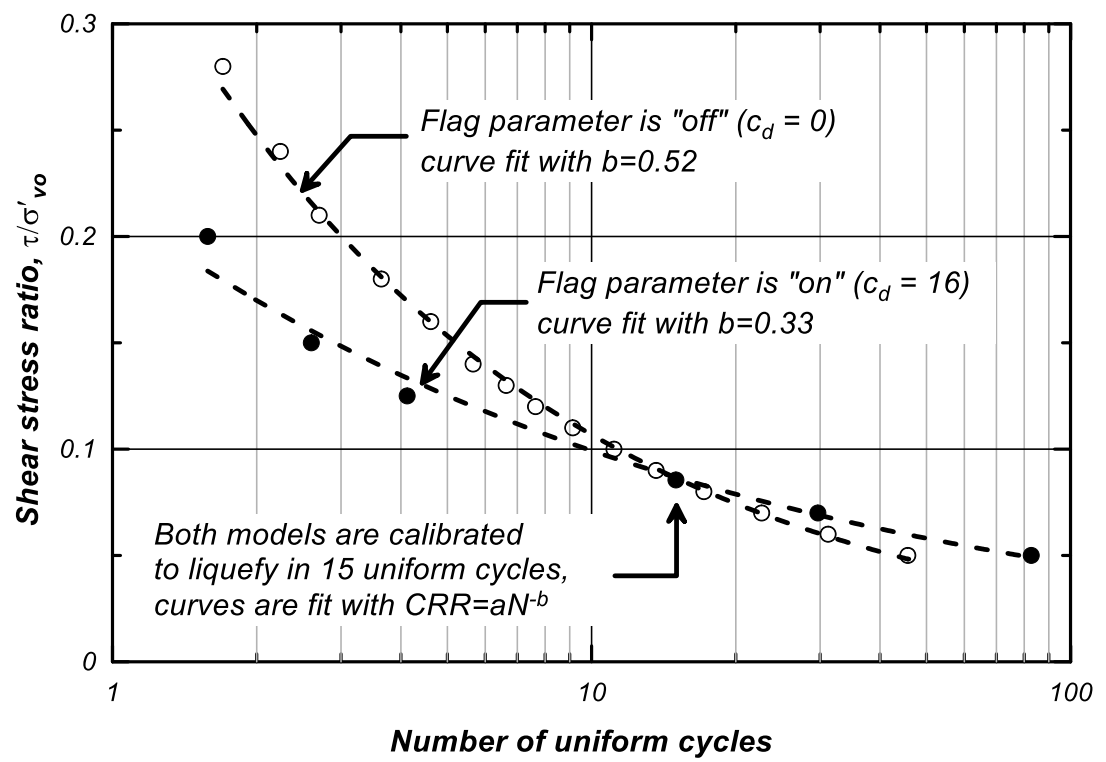

Figure 5. Effects of input parameter $\mathrm{C}_{\mathrm{d}}$ on the number of uniform loading cycles to trigger liquefaction 


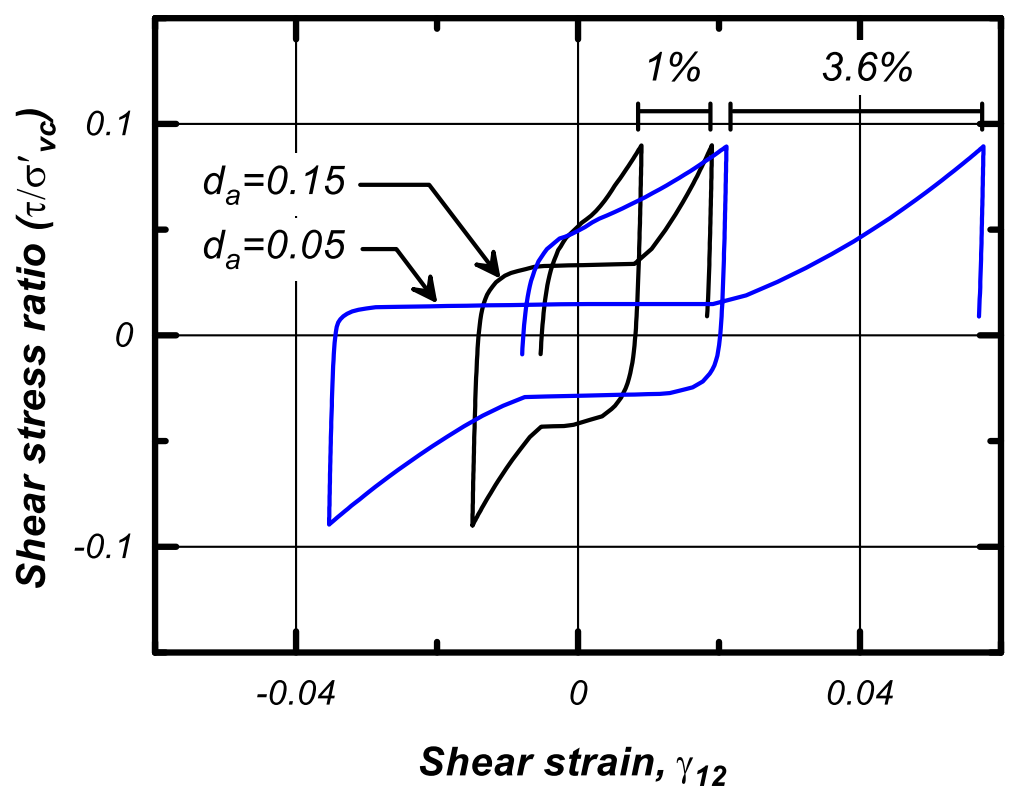

Figure 6. Effects of input parameter $\boldsymbol{d}_{\mathbf{a}}$ on dilation rate 


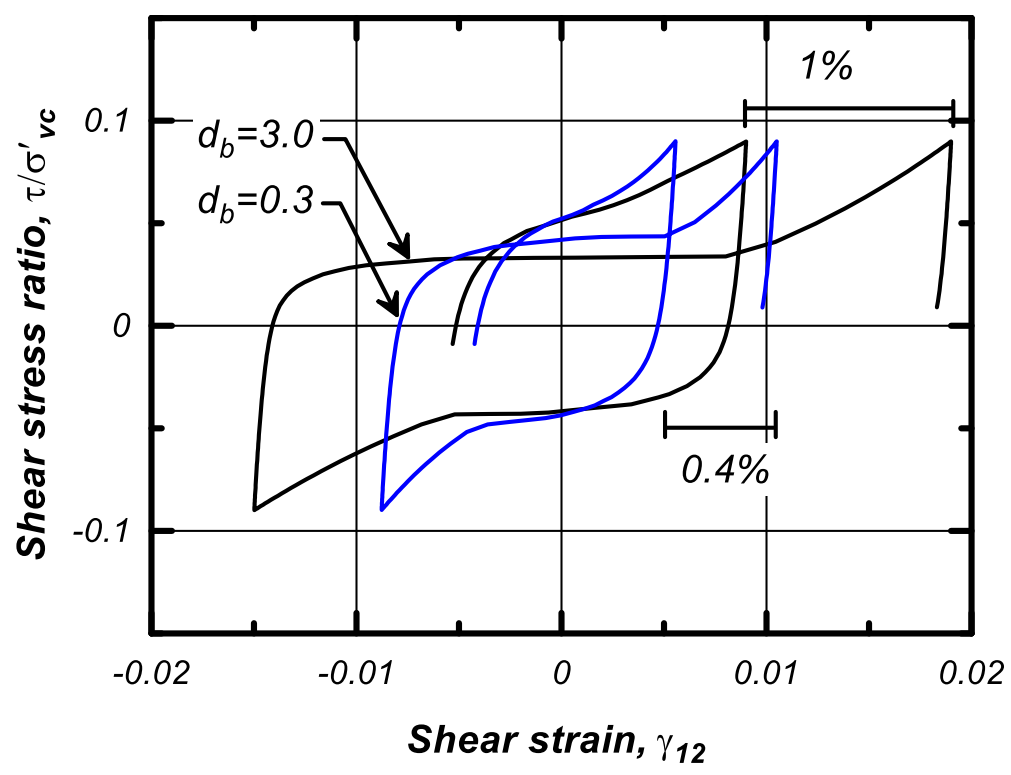

Figure 7. Effects of input parameter $\boldsymbol{d}_{\mathbf{b}}$ (fabric damage) on dilation rate 
(a)

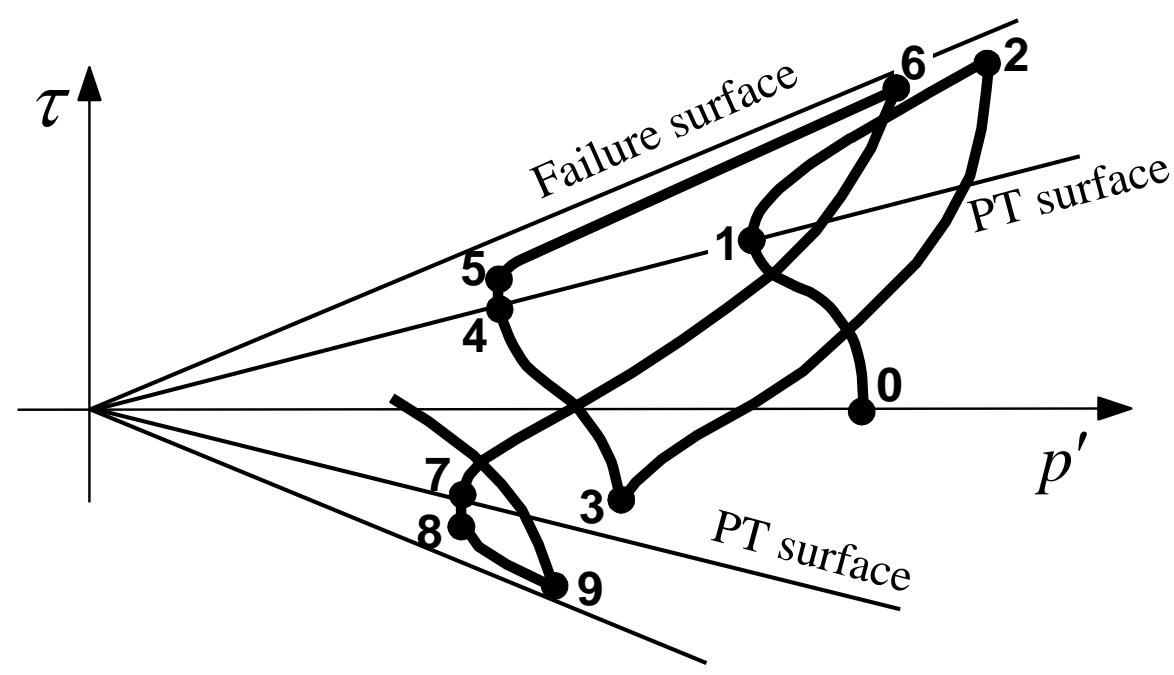

(b)

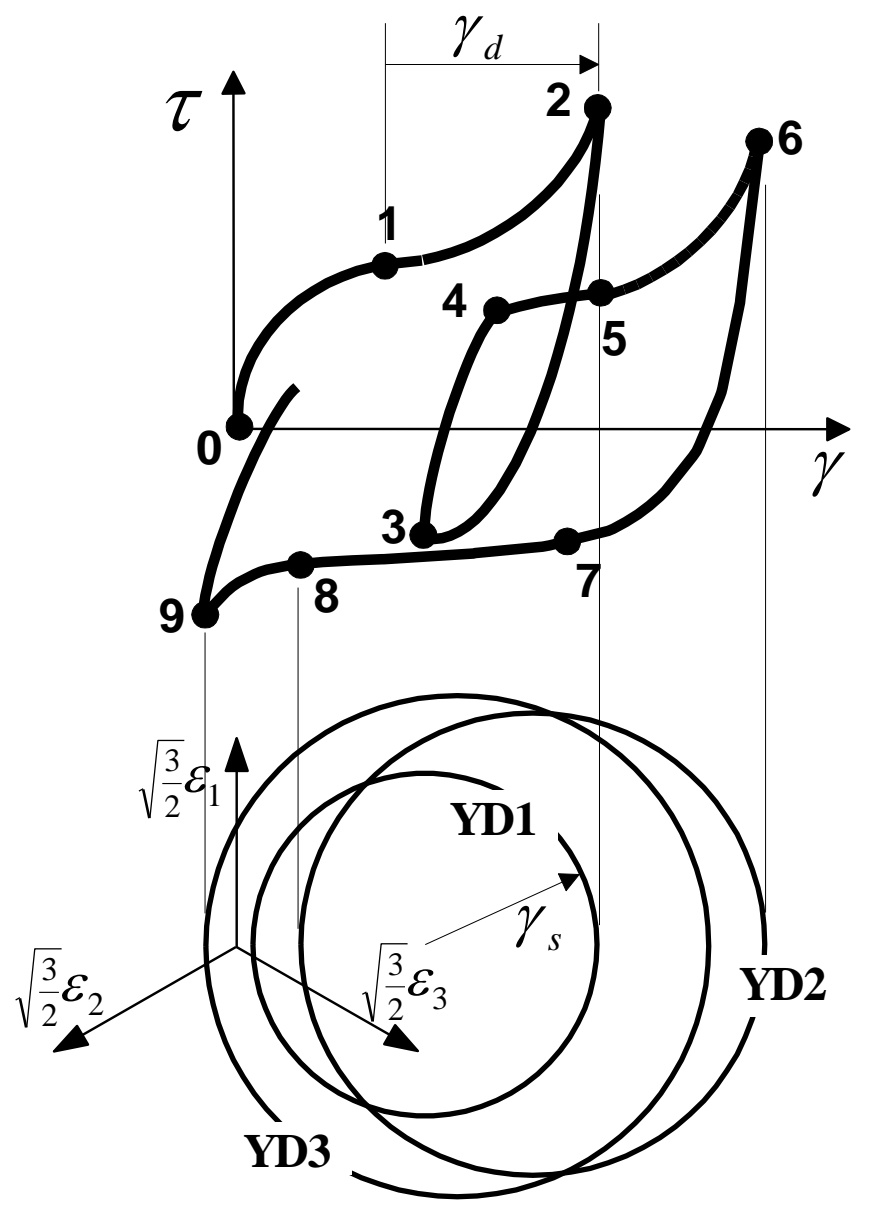

Figure 8: Schematic of the neutral phase in model response showing (a) octahedral stress $\tau$ - effective confinement $p^{\prime}$ response, (b) $\tau$ - octahedral strain $\gamma$ response, and (c) configuration of yield domain. 

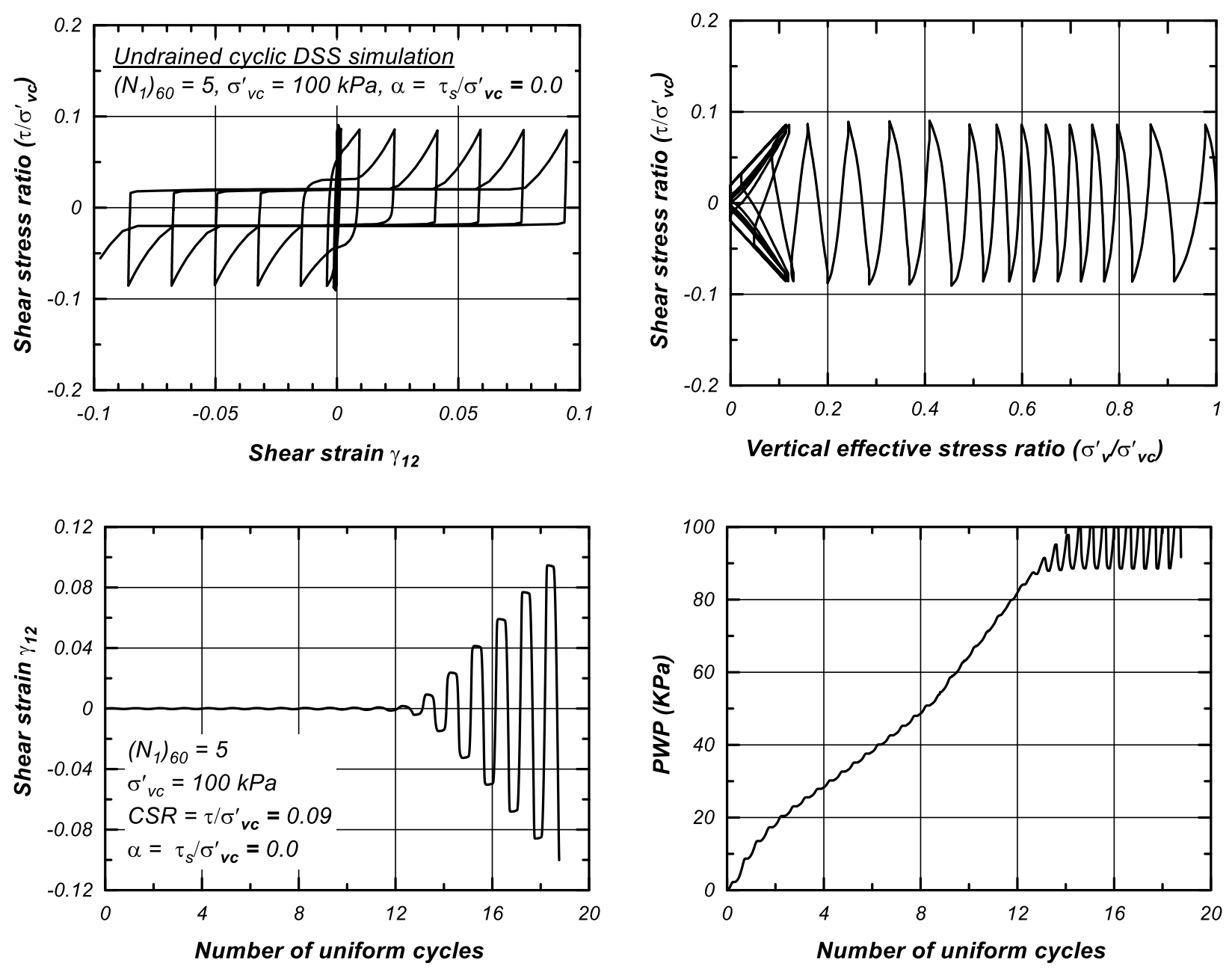

Figure 9. Example model response in undrained cyclic simple shear loading for $\left(\mathrm{N}_{1}\right)_{60}=5$ 


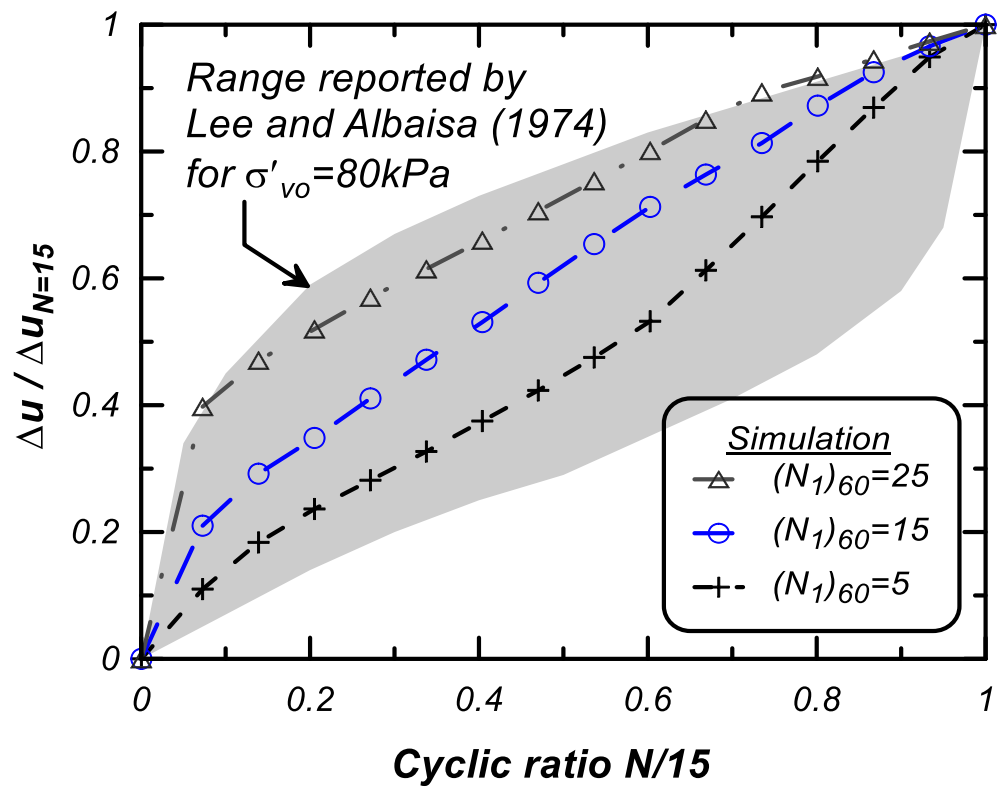

Figure 10. Model predicted rate of pore pressure generation in DSS simulations for different relative densities at $\sigma^{\prime}{ }_{v c}=100 \mathrm{kPa}$ compared with the range expected from experimental observations 


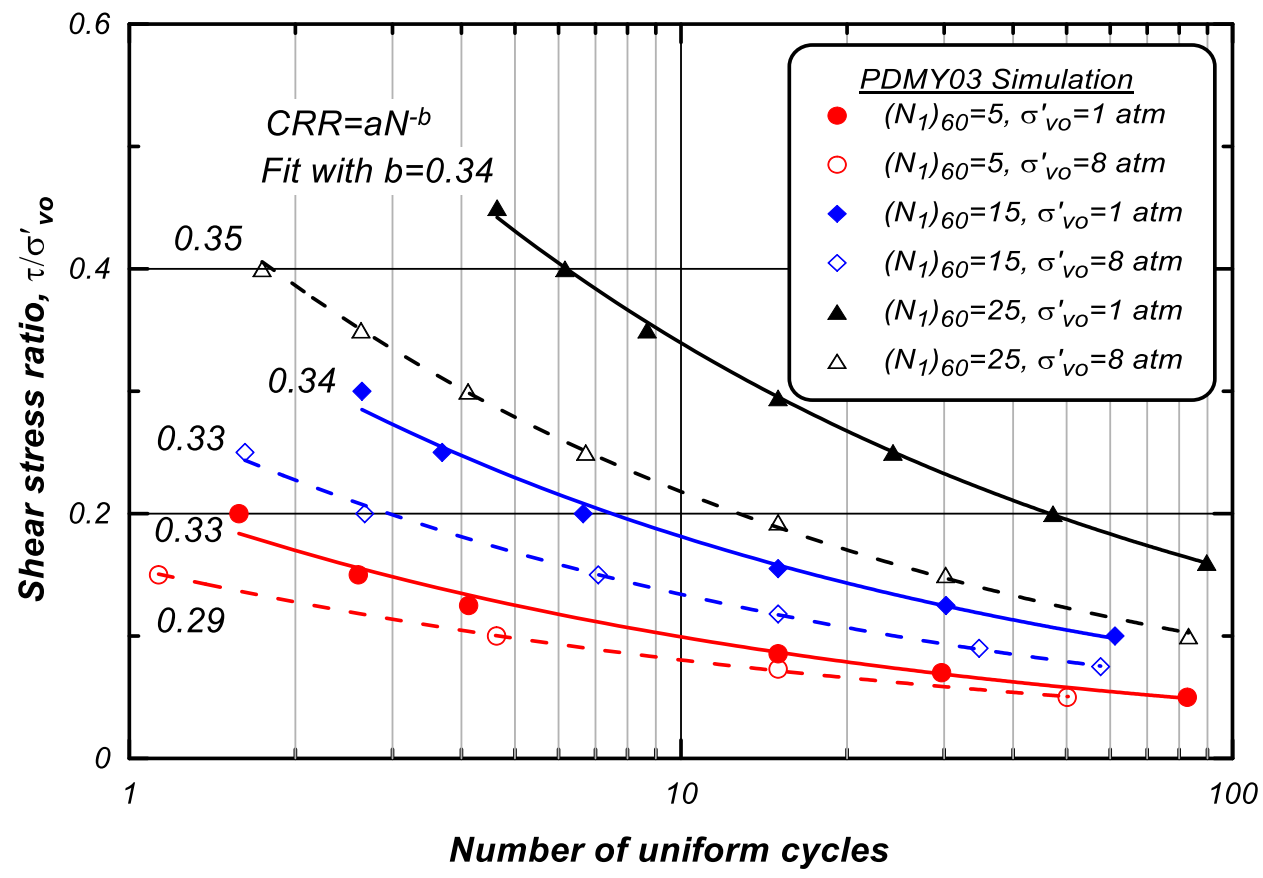

Figure 11. Cyclic shear stress ratio versus number of uniform loading cycles in undrained DSS simulations to trigger liquefaction defined as single-amplitude shear strain of $3 \%$ (no static shear stress $\alpha=0$ ) 


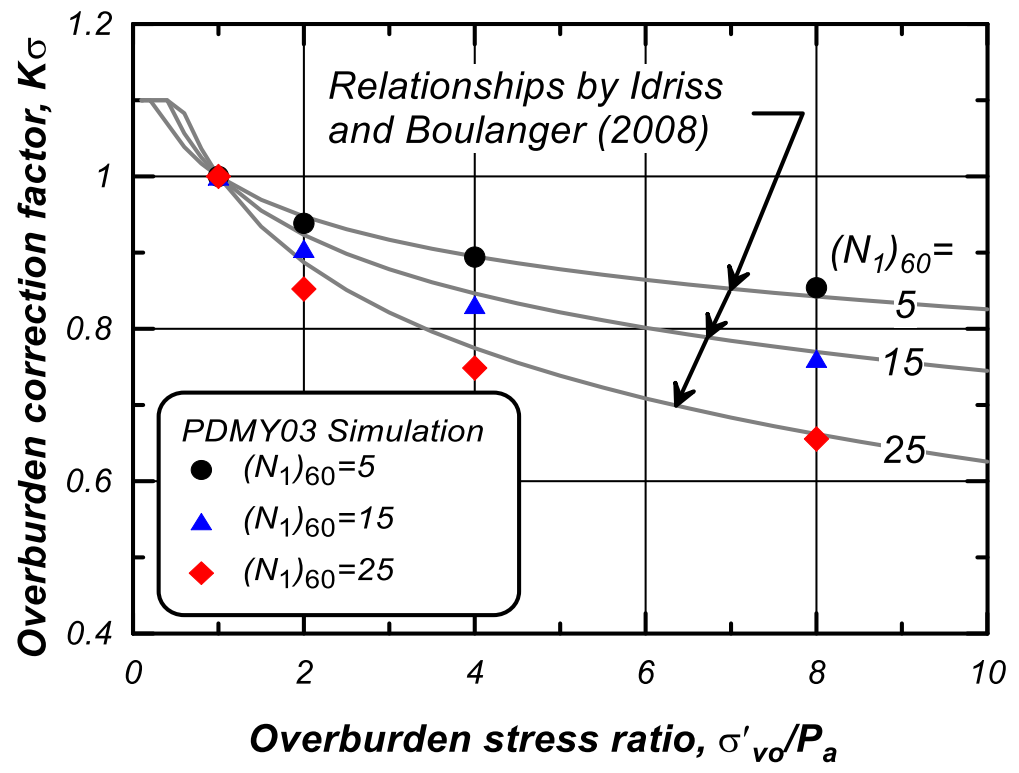

Figure 12. K $\sigma$ relationships derived from model simulations compared to relationships by Idriss and Boulanger (2008). 


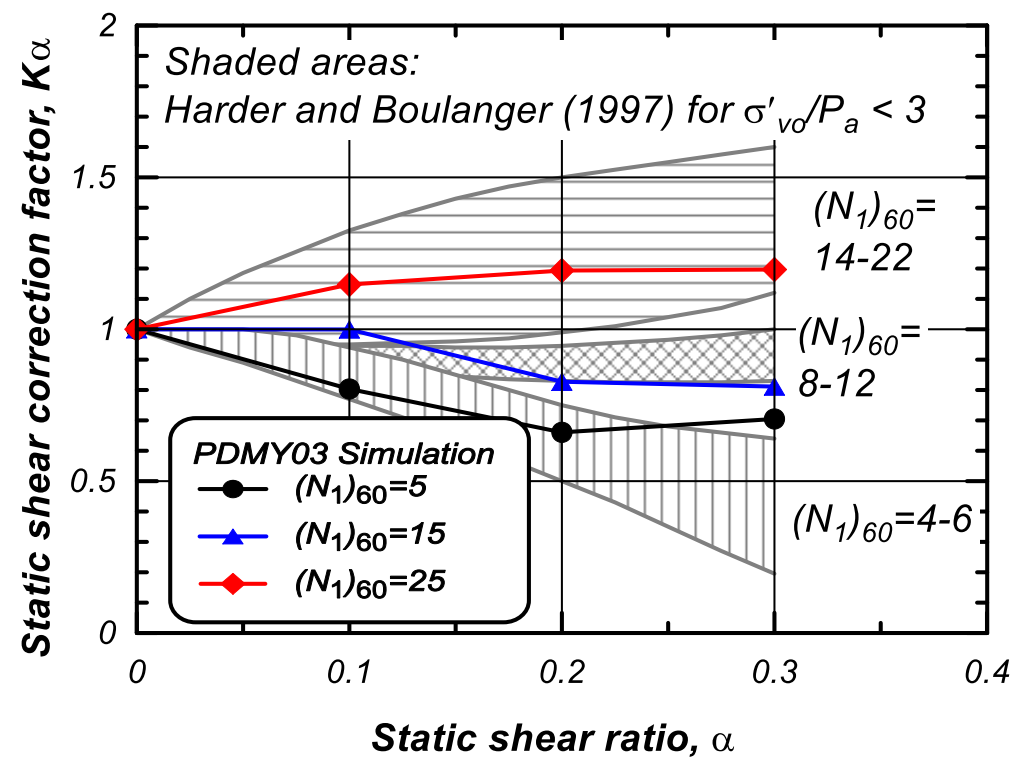

Figure 13. Experimental trends for different $\left(\mathrm{N}_{1}\right)_{60}$ values and $\sigma^{\prime}{ }_{v c}<3$ atm from Harder and Boulanger (1997) and model generated static shear stress correction factors $(\mathrm{K} \alpha)$ for $\sigma_{\mathrm{vc}}^{\prime}=1 \mathrm{~atm}$ 